\section{Mudanças climáticas globais: as dimensões humanas em perspectiva*}

\author{
Douglas Sathler ${ }^{\star *}$ \\ Ruibran dos Reis ${ }^{* * *}$
}

\begin{abstract}
HOGAN, D. J.; MARANDOLA Jr., E. População e mudança climática: dimensões humanas das mudanças ambientais globais. Campinas: Núcleo de Estudos da População - Nepo, 2009. 292 p.
\end{abstract}

Imaginem um mundo diferente, onde a palavra sustentabilidade é levada a sério em seu sentido mais profundo. Nesse mundo, o verde é tido como um bem precioso por todos e a vida pulsa no ritmo da natureza. Muitos shoppings foram substituídos por parques, deixando de ser o destino privilegiado do final de semana. As famílias que possuem mais de um carro na garagem são olhadas com desconfiança pelos seus vizinhos. Os fazendeiros exibem com orgulho a quantidade de área reflorestada dentro de suas propriedades e não mais a quantidade de cabeças de gado ou o tamanho de suas culturas. O status não é mais econômico e material e a sociedade descobriu outros valores diante da consciência de que é preciso cuidar e respeitar a nossa casa. Nesse mundo limpo, as mudanças climáticas globais estão em fase de superação. Difícil de imaginar?

Mesmo diante de uma realidade tão distante, sonhar é preciso. Isso não significa que chegaremos exatamente onde imaginamos, mas cada passo dado em direção a essa abstração será recompensado com um mundo melhor para se viver.

Nessa mesma linha de raciocínio, o livro População e mudança climática: dimensões humanas das mudanças ambientais globais traz na introdução a seguinte afirmação elaborada pelo prof. Daniel Hogan:

O mundo sustentável, resiliente e adaptado à mudança climática não será um mundo menos alegre, menos democrático ou com menos oportunidades de auto-realização. Mas será diferente. É preciso abrir mão do individualismo absoluto, cultivando o planejamento, aceitando os limites à ação humana e buscando a satisfação em valores menos materialistas, para que o desafio da mudança climática tenha resposta (p.18).

Este tipo de transformação exige um esforço de todos os segmentos da sociedade e, sendo assim, o envolvimento da comunidade científica é de extrema importância, considerando-se toda a complexidade embutida nesse tipo de discussão.

Nas últimas décadas, verificam-se avanços significativos com relação à questão ambiental, sobretudo do ponto de vista da legislação e da criação de diversos instrumentos com impactos evidentes na melhoria da qualidade ambiental. Entretanto, ainda precisamos trabalhar mais, uma vez que a natureza tem oferecido sinais de transformação, sobretudo na perspectiva do clima.

O segundo relatório do Intergovernmental Panel on Climate Change (IPCC), divulgado em 1995, já deixava claro que a temperatura da Terra aumentou $0,7^{\circ} \mathrm{C}$ desde a revolução industrial. Além disso, o documento demonstrou que há uma probabilidade de $90 \%$ de as atividades antrópicas serem responsáveis pelas mudanças climáticas globais.

Nesse contexto, as mudanças climáticas globais têm motivado o interesse de cientistas de todas as partes do mundo, haja vista a enorme quantidade de trabaIhos científicos produzidos recentemente,

\footnotetext{
* Este Livro faz parte dos trabalhos desenvolvidos pelo GT População, Espaço e Ambiente da Abep.

** Geógrafo (IGC-UFMG) e doutor em Demografia (Cedeplar-UFMG). Pesquisador da Fundação João Pinheiro (FJP-MG).

${ }^{* * *}$ Meteorologista (UFRJ) e doutor em Geografia (PUC-Minas). Professor do curso de pós-graduação do Tratamento da Informação Espacial (PUC-Minas). Coordenador do Centro de Meteorologia MinasTempo.
} 
com destaque para os relatórios do IPCC, e a participação ativa de pesquisadores de diversas áreas do conhecimento nos inúmeros congressos, seminários e conferências.

Entretanto, ainda existe carência de pesquisas que considerem o fenômeno em conjunto com suas dimensões humanas, seja do ponto de vista da demografia, seja de outras ciências que também dialogam com essa temática. Assim, o livro População e mudança climática: dimensões humanas das mudanças ambientais globais possui o mérito de chamar a atenção para esta lacuna, pois aborda o fenômeno sob a perspectiva que, no final das contas, realmente interessa: a perspectiva humana.

O livro é dividido em três partes de acordo com a natureza das contribuições: elementos teórico-metodológicos; população e desenvolvimento; e urbanização e mudanças climáticas.

$\mathrm{Na}$ primeira parte são apresentados alguns elementos teóricos, incluindo uma discussão instigante sobre um dos conceitos mais importantes no que diz respeito aos debates recentes sobre as mudanças climáticas e a dinâmica populacional: a vulnerabilidade. Após este primeiro momento, o livro se volta para o tema "mudanças climáticas, extremos atmosféricos e padrões de risco a desastres hidrometeorológicos". Ainda na primeira parte, também são exploradas algumas metodologias de integração de dados sociodemográficos e ambientais, para análise da vulnerabilidade socioambiental em áreas urbanas no contexto das mudanças climáticas.

A segunda parte aborda alguns aspectos sobre a relação do homem com o meio ambiente, apoiando-se no estudo de alguns casos específicos. As discussões também consideram o tema população e mudança climática sob a perspectiva do longo prazo, extrapolando os estudos que relacionam a dimensão humana e demográfica apenas com eventos catastróficos, a exemplo do possível aumento e intensificação de furacões, tornados, inundações e secas.

Por fim, uma coletânea de artigos sobre urbanização e mudanças climáticas compõe a terceira parte do livro. Este tipo de discussão é de grande relevância, já que a organização da sociedade brasileira em cidades, muitas vezes, desconsiderou os fenômenos ambientais e atmosféricos. Assim, o que se tem observado nos últimos anos é um aumento significativo em catástrofes urbanas. Os desastres ocorridos recentemente na cidade de São Paulo pode ser um laboratório para compreender as ações do homem em relação ao meio ambiente.

O livro oferece uma boa oportunidade de se aprofundar em questões mais relevantes que cercam o tema população e mudança climática. De acordo com o prof. Daniel Hogan, no seu conjunto, os capítulos do livro indicam a importância do estudo sobre a mudança climática e seu relacionamento com as questões populacionais.

Trata-se de um belo esforço de pesquisadores de várias instituições acadêmicas e de pesquisa para fomentar este tipo de debate no país, que, com certeza, trará ótimos desdobramentos do ponto de vista de estudos futuros.

Ao final, segue a relação de autores que participaram da elaboração do livro: Alisson Flávio Barbieri (UFMG), Andrea Ferraz Young (Unicamp), Bernardo Lanza Queiroz (UFMG), César Augusto Marques da Silva (Ipea), Daniel Joseph Hogan (Unicamp), Diego de Freitas Rodrigues (UFSCar), Eduardo Marandola Jr. (Unicamp), Heloísa Soares Moura Costa (UFMG), Humberto Prates da Fonseca Alves (Unifesp), Leonardo Freire de Mello (Universidade do Vale do Paraíba), Lucí Hidalgo Nunes (Universidade Estadual de Campinas), Magda Luzimar de Abreu (UFMG), Marcelo Vargas (UFSCar), Ricardo Ogima (Fundação João Pinheiro), Roberto Luiz do Carmo (Unicamp) e Wellington Lopes Assis (UFMG).

Recebido para publicação em 04/03/2010 Aceito para publicação em 23/03/2010 